\title{
THE MEASURE OF TRUST IN INTERNATIONAL RELATIONS. WEST - EAST RELATIONS CASE
}

\begin{abstract}
The object of research is the trust problem in the relations of the East and the West. The author in detail analyzes the phenomenon of trust, its principles and distinctive signs. Special attention is paid to conditions of formation of trust as on micro (between individuals) and at the macro level (between societies). The author connects the trust problem with a categorization "friend-or-foe", considered in the civilization aspect of the subject. Thus, the author in the research used the case study method and content analysis. The novelty of research consists in approach to understanding intensity between civilizations of the East and the West through a problem of the possibility of confidential relations between them. The author comes to a conclusion that in the modern international relations there is a paradoxical situation: the trust measure between the countries decreases, in volume time as it is possible to cope with new calls and threats only through consolidation of the world community on the basis of mutual trust.
\end{abstract}

\section{Key words}

trust, the East and the West, "friend-or-foe", international relations

The specifics of relationship between the East and the West have always occupied the minds of researchers. Various cultural and civilization approaches explained difficulties in communication of east and western societies with cultural, linguistic and religious features. Today under the influence of globalization

* Zvyagina Daria, the specialist the cultural study, the bachelor of the international relations, PhD of political sciences. Senior research associate of the Center of the Atlantic researches and international security of Institute of actual international problems. Senior teacher of department of Political science and political philosophy of Diplomatic academy Russian Foreign Ministry. e-mail: d.zvyagina89@gmail.com. 